Article

\title{
Remotely Sensed Active Layer Thickness (ReSALT) at Barrow, Alaska Using Interferometric Synthetic Aperture Radar
}

\author{
Kevin Schaefer 1,*, Lin Liu ${ }^{2}$, Andrew Parsekian ${ }^{3}$, Elchin Jafarov ${ }^{1}$, Albert Chen ${ }^{4}$, \\ Tingjun Zhang ${ }^{1,5}$, Alessio Gusmeroli ${ }^{6}$, Santosh Panda ${ }^{6}$, Howard A. Zebker ${ }^{4}$ and Tim Schaefer ${ }^{7}$
}

1 National Snow and Ice Data Center, Cooperative Institute for Research in Environmental Sciences, University of Colorado at Boulder, Boulder, CO 80309, USA; E-Mails: elchin@nsidc.org (E.J.); tzhang@nsidc.org (T.Z.)

2 Earth System Science Programme, Faculty of Science, The Chinese University of Hong Kong, Hong Kong, China; E-Mail: liulin@cuhk.edu.hk

3 Department of Geology and Geophysics, University of Wyoming, Laramie, WY 82070, USA; E-Mail: aparseki@uwyo.edu

4 Department of Geophysics, Stanford University, Stanford, CA 94305, USA; E-Mails: acchen@stanford.edu (A.C.); zebker@stanford.edu (H.A.Z.)

5 College of Earth and Environmental Sciences, Lanzhou University, Lanzhou 730000, China

6 International Arctic Research Center, University of Alaska, Fairbanks, 99775 AK, USA; E-Mails: agusmeroli@alaska.edu (A.G.); skpanda@alaska.edu (S.P.)

7 Galmont Consulting, Chicago,60602 IL, USA; E-Mail: timschaef60016@yahoo.com

* Author to whom correspondence should be addressed; E-Mail: kevin.schaefer@nsidc.org; Tel.: +1-303-492-8869.

Academic Editors: Santonu Goswami, Daniel J. Hayes, Guido Grosse, Benjamin Jones and Prasad S. Thenkabail

Received: 3 August 2014 / Accepted: 10 February 2015 / Published: 27 March 2015

\begin{abstract}
Active layer thickness (ALT) is a critical parameter for monitoring the status of permafrost that is typically measured at specific locations using probing, in situ temperature sensors, or other ground-based observations. Here we evaluated the Remotely Sensed Active Layer Thickness (ReSALT) product that uses the Interferometric Synthetic Aperture Radar technique to measure seasonal surface subsidence and infer ALT around Barrow, Alaska. We compared ReSALT with ground-based ALT obtained using probing and calibrated, $500 \mathrm{MHz}$ Ground Penetrating Radar at multiple sites around Barrow. ReSALT accurately reproduced observed ALT within uncertainty of the GPR and probing data
\end{abstract}


in $\sim 76 \%$ of the study area. However, ReSALT was less than observed ALT in $\sim 22 \%$ of the study area with well-drained soils and in $\sim 1 \%$ of the area where soils contained gravel. ReSALT was greater than observed ALT in some drained thermokarst lake basins representing $\sim 1 \%$ of the area. These results indicate remote sensing techniques based on InSAR could be an effective way to measure and monitor ALT over large areas on the Arctic coastal plain.

Keywords: permafrost; permafrost dynamics; active layer thickness; barrow; interferometric synthetic aperture radar; ground penetrating radar

\section{Introduction}

Air temperatures above the Arctic Circle are increasing at a rate roughly twice the global average and resulting in warmer permafrost and deeper active layers [1-3]. Ground-based measurements indicate rising permafrost temperatures across the Arctic over the last several decades, with northerly sites warming faster than more southerly sites [4,5]. Active layer thickness (ALT) is defined as the maximum annual thaw depth of soil over permafrost [6] and is designated as an essential climate variable to monitor permafrost regions. Changes in ALT are less conclusive, with some sites showing increases, but others showing no trend at all with large inter-annual variability [7-9].

Ground-based measurements of ALT are coordinated by the Circumpolar Active Layer Monitoring (CALM) network as part of the Global Terrestrial Network for Permafrost (GTN-P) [10]. The CALM network measures ALT at 260 sites either using a mechanical probe or a vertical array of temperature sensors $[7,11,12]$. There are only five to six CALM sites for every million $\mathrm{km}^{2}$ of permafrost area in the Northern Hemisphere, with a strong bias towards regions along the Arctic coastline in Alaska and Central Siberia. Remote sensing offers the possibility of measuring ALT over large, inaccessible areas to complement the in situ measurements at CALM sites.

ALT remote sensing techniques typically use empirical relationships between probe measurements and a physical attribute and use remotely sensed data of that attribute to extrapolate ALT over a larger area. For example, Gangodagamage et al. [13] related probe data to relative height and used LiDAR data to extrapolate ALT over a $5 \mathrm{~km}^{2}$ area near Barrow. Nelson et al. [14] related probe data to vegetation type and used remotely sensed vegetation type to extrapolate ALT along a $100 \mathrm{~km}$ stretch of the Kuparuk River, Alaska. Pastick et al. [15] related probe data to ground resistivity and used helicopter-borne measurements of ground resistivity to extrapolate ALT over $33,000 \mathrm{~km}^{2}$ area near Yukon Flats, Alaska. These techniques all require extensive probing data to establish the required empirical relationships.

In contrast, the Remotely Sensed Active Layer Thickness (ReSALT) retrieval algorithm uses the Interferometric Synthetic Aperture Radar (InSAR) technique to estimate ALT from seasonal ground subsidence, without using empirical relationships with probing data. InSAR has been used to measure vertical surface displacement in permafrost areas [16-20]. Liu et al. [19] used the InSAR technique to measure long-term ground subsidence rates near Prudhoe Bay, Alaska resulting from the melting of excess ground ice near the permafrost table. Liu et al. [21] extended this to estimate ALT from measured seasonal subsidence using a simple model of soil expansion resulting from the freezing and thawing of the active layer (see details below). 
Here we validate ReSALT against calibrated Ground Penetrating Radar (GPR) measurements of ALT, determine where the InSAR technique works best to estimate ALT, and identify improvements to our retrieval algorithms. In a GPR measurement, radio frequency energy is transmitted and reflected at the interfaces between soil layers of contrasting physical properties, in this case the contrast in relative dielectric permittivity between liquid and frozen water at the permafrost table. In August of 2013, we collected GPR measurements of ALT around Barrow, Alaska over a domain encompassing all major scientific research sites in the area (Figure 1), including two CALM sites. The landscape is typical of the Arctic coastal lowland on the North Slope of Alaska with many drained and active thermokarst lakes and ubiquitous ice wedges and polygons. The southern boundary is determined by edges of the satellite scenes used in this study and the northern edge by the Arctic Ocean.

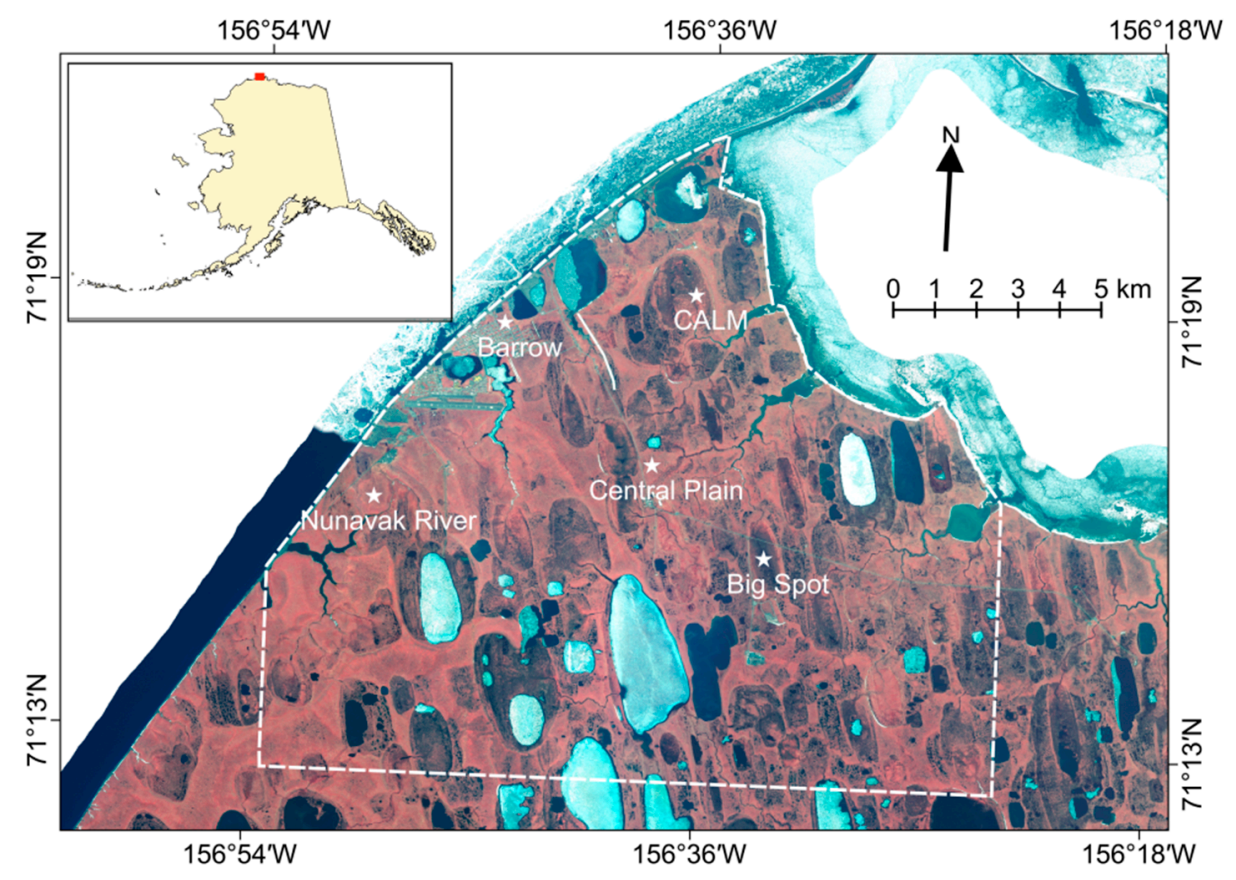

Figure 1. The Remotely Sensed Active Layer Thickness (ReSALT) domain around Barrow, Alaska (dashed line) and the locations of the four validation sites.

\section{Methods}

\subsection{Validation Sites}

We selected four sites to validate ReSALT representing a range of environmental conditions commonly observed in the Barrow area (Figure 1 and Table 1). Big Spot consists of a series of drained thermokarst lake basins (DTLBs) of varying ages and got its name from a large spatial anomaly in ReSALT values in one of the four DTLBs. We chose this site because it represented conditions typical of DTLBs around Barrow and because the largest ReSALT values for the entire domain occurred in the Big Spot DTLB. The CALM site consists of two large DTLBs separated by a narrow strip of undisturbed tundra. We chose this site to evaluate conditions within and outside of large DTLBs and because of the availability of long-term measurements of ALT at the two Barrow sites in the CALM network, U1 and U2 [7]. The Central Plain site is a matrix of high-center polygons with fully saturated soil and standing water over the ice wedges. We selected the Central Plain site because it represented 
typical undisturbed tundra around Barrow and conditions most similar to the idealized tundra represented in the ReSALT retrieval algorithm. The Nunavak River site covers the upper portion of the Nunavak drainage basin, just south of the Barrow airport. The site consists of undisturbed tundra surrounded on three sides by the Nunavak River and its tributaries. The undisturbed tundra consists of a matrix of high-centered polygons similar to Central Plain, but with less standing water over the ice wedges. The elevation drops 3-4 m near the Nunavak River, with fully saturated soils and no polygons. We selected this site because we expected a mix of saturated and unsaturated soil conditions and because we measured the smallest ReSALT values for the entire domain around the Nunavak River. In summary, the four sites represented typical undisturbed tundra conditions (Central Plain), the smallest ReSALT values and drained soils (Nunavak River), the largest ReSALT values and typical DTLB conditions (Big Spot), and large DTLBs with the greatest amount of historical ALT observations (CALM).

Table 1. ReSALT Validation Sites.

\begin{tabular}{ccccc}
\hline Site & Latitude (deg) & Longitude (deg) & Date in 2013 & Selection Criteria \\
\hline Big Spot & 71.252975 & -156.557655 & $11-12$ August & $\begin{array}{c}\text { Largest ReSALT values; } \\
\text { typical DTLB conditions }\end{array}$ \\
\hline CALM & 71.31202 & -156.609585 & $14-15$ August & Large DTLBs; historical ALT observations \\
\hline Central Plain & 71.273177 & -156.634896 & $12-13$ August & Typical undisturbed tundra \\
\hline Nunavak River & 71.263803 & -156.820302 & 10 August & $\begin{array}{c}\text { Lowest ReSALT values; } \\
\text { saturated and unsaturated soils }\end{array}$ \\
\hline
\end{tabular}

\subsection{CALM Data}

We used ALT data from the U1 and U2 CALM sites to compare with ReSALT. U1 consists of a $1-\mathrm{km}$ square grid of measurement sites, called nodes, placed $100 \mathrm{~m}$ apart where ALT has been measured using probing since 1995 [22]. U2, also known as the Cold Regions Research and Engineering Laboratory (CRREL) site, consists of a 10-m square plot of 320 randomly placed probe measurements [11]. We calculated the 1995 to 2013 average ALT at each node and projected these onto the corresponding ReSALT pixel. We treated the entire $\mathrm{U} 2$ plot as a single pixel and at $\mathrm{U} 1$ we treated each node as a pixel, but did not include node $61\left(156^{\circ} 35^{\prime} 21.78^{\prime \prime} \mathrm{W}, 71^{\circ} 18^{\prime} 33.06^{\prime \prime} \mathrm{N}\right)$ because we used it as our reference point and nodes 7, 110, and 121 because they contained too many missing values. In addition, we did not include three of the U1 nodes that fell onto areas with no coherent InSAR signal. The CALM data at U1 and U2 sites resulted in a total of 115 pixels for comparison with ReSALT.

We estimated uncertainty in the CALM data based on probing uncertainty and spatial representation error. We assumed a probing uncertainty of $3.0 \mathrm{~cm}$ for all CALM data due to uncertainty in the thickness of the transition layer at the permafrost table and uncertainty in thumb placement when using the probing rod. We included spatial representation error due to the fact that the probe measurements represent the ALT for a single point while ReSALT represents an area average within a $30 \mathrm{~m}$ by $30 \mathrm{~m}$ pixel. The U2 ALT value includes the standard deviations of all 320 probe measurements taken each year, so we estimated the spatial representation error for all nodes as the square root of the average variance of the 320 probing measurements: $7.3 \mathrm{~cm}$. This assumes that the spatial variability within the U2 plot is representative of the spatial variability within a ReSALT pixel for the U1 nodes. These two 
uncertainty sources are independent of one another, so the total uncertainty in the CALM ALT values is the probing and spatial representation uncertainty added in quadrature: $7.9 \mathrm{~cm}$.

\subsection{Ground Penetrating Radar (GPR)}

We collected a total of $\sim 15 \mathrm{~km}$ of ALT measurements using $500 \mathrm{MHz}$ GPR and $\sim 1.5 \mathrm{~km}$ of probing data at the four validation sites in August of 2013 to compare with ReSALT. We went in August to approximate the time of year when the active layer would be at its maximum thickness. GPR was ideal for acquiring ALT at very high spatial density over the long distances needed for comparison with ReSALT. GPR uses pulsed radio-frequency electromagnetic waves to noninvasively image the subsurface. Energy emitted from a transmitting antenna travels into the ground and some of the energy is reflected back towards the receiving antenna at the surface, which records the travel time. The digitized record of reflected energy, known as a trace, is made at regular time intervals as the GPR unit is pulled along the ground and the graphic representation of a series of traces is a radargram. GPR technology has a long history of measuring ALT with acceptable accuracy in comparison with probe data [23-27].

We used a Malå CUII GPR unit with a $500 \mathrm{MHz}$ shielded antenna and set the time interval between traces at a constant $0.5 \mathrm{~s}$ so that the distance between the GPR traces was less than $0.5 \mathrm{~m}$ at an average walking pace. The total time window for the GPR each acquisition was $76 \mathrm{~ns}$ at a sampling rate of $5 \mathrm{GHz}$. We linked a handheld Global Positioning System (GPS) unit with a precision of $\sim 2 \mathrm{~m}$ (as reported by the GPS) to the GPR instrument to record the location of each trace. The reflection at the bottom of the active layer was clearly visible in the raw data, so we did not require any data filters. Instead, we applied the standard time-zero correction by setting the position of the first arrival as time-zero for each trace and digitized the unambiguous reflection event directly from the radargrams by hand. We manually digitized the radar reflections, commonly known as picking, as a quality control measure to verify the signals and reduce interpretation errors due to spurious reflections.

ReSALT represents an area-average ALT per pixel while the GPR traces represent ALT values for a footprint of less than $0.15 \mathrm{~m}^{2}$, based on the antenna frequency and physical properties of the active layer. To compare with ReSALT, we projected the GPR traces onto the InSAR pixels by calculating the average of all GPR traces in each pixel along the GPR tracks, with an average of 40 traces per pixel. These traces transect each pixel to provide a reasonable area average value for comparison with ReSALT. We utilized a high-density comparison of 50 co-located GPR and probe data points along a $25 \mathrm{~m}$ survey line to verify that the average of the GPR traces is a valid representation of the average ALT in a pixel (see Section 3.2).

We used mechanical probing roughly every kilometer to calibrate the GPR wave velocity used to convert the two way transit time to ALT. For each calibration probe we took the average of three probe measurements adjacent to the GPR antenna. In addition, we laid a 100-m survey line along segments of the GPR track and used a mechanical probe to make a single ALT measurement every meter. We used these high-density probe measurements to calibrate the average wave velocity and standard deviations at each study site. We estimated uncertainty in GPR ALT due to soil water variability by propagating the standard deviation of wave velocity through the calculation of ALT from the transit time.

We also calculated volumetric water content (VWC) of the active layer soil at 3-8 calibration points per site where the probe measurement was exactly co-located with a GPR trace. For most calibration 
points we used the Engstrom et al. [28] empirical VWC model developed for active layer soils in Barrow. We used the Parsekian et al. [29] VWC model for peat locations, such as the residual ponds at Big Spot and CALM, and the Topp et al. [30] model for sandy/coarse sediments, such as near the Nunavak River. Liu et al. [31] provide details on the calculations. The estimated VWC represents an average value for the entire active layer and can be used to estimate ALT from seasonal subsidence.

We included uncertainty due to the fact that the GPR measurement represents the ALT for 2013 only while ReSALT represents the 2006-2010 average ALT. We estimated the uncertainty associated with comparing a single value to a time average as $4.7 \mathrm{~cm}$, based on the temporal standard deviation of the ALT measured at the U1 CALM site from 1995 to 2008. This assumes that interannual variability at the CALM site was representative for the entire domain. The uncertainty sources are independent of one another, so the total uncertainty in the GPR ALT values is the wave velocity and time-average uncertainty added in quadrature.

\subsection{InSAR Techniques}

Because liquid water is denser than ice, the ground surface around Barrow rises in winter as water in the active layer freezes and subsides in summer as the active layer thaws. We measure this seasonal frost heave and subsidence using InSAR and estimate ALT in a two-step process, collectively referred to as the ReSALT retrieval algorithm. First we used InSAR to estimate the seasonal summer surface subsidence. Next, we used a model of the distribution of water within the active layer to estimate ALT from the seasonal surface subsidence. Liu et al. [21] described the ReSALT retrieval algorithm in detail, so here we included only a brief summary.

InSAR uses phase differences between Synthetic Aperture Radar (SAR) images acquired at different times to produce interferograms that map surface deformation in the radar line-of-sight direction. To measure the seasonal subsidence with InSAR, we first collected the Phased Array type L-band Synthetic Aperture Radar (PALSAR) scenes from the Advanced Land Observation Satellite (ALOS) for the Barrow domain. We processed the raw data into focused SAR images and formed interferograms from pairs of co-registered SAR scenes. We then used multilook processing area averaging to increase coherence and reduce uncertainty, resulting in a final resolution of $\sim 30 \mathrm{~m}$. The resulting interferograms are georeferenced using satellite orbit data and a digital elevation model. Zebker et al., [32] describe the processing procedures in detail.

We used a total of 9 PALSAR scenes between 2006 and 2010 and formed 20 interferograms with good coherence and without contamination by obvious ionospheric artifacts (Appendix A). We used only scenes acquired between June and September to avoid extraneous InSAR signals due to snow cover. Since surface deformation in our study area is dominated by subsidence in summer and uplift in winter, we converted line-of-sight measurements to vertical subsidence using the radar incidence angle [19]. Relative InSAR measurements over a large area are converted to absolute subsidence by using one or more reference points where the absolute subsidence is known. We normally use exposed bedrock as a reference point, which has negligible vertical motion over the time period covered by the InSAR data. However, there is no exposed bedrock near Barrow, so we used node 61 in the U1 CALM site grid as the reference point. We chose node 61 because it was near the center of the CALM grid and because it represented conditions most like the ideal conditions in our retrieval algorithm. We calculated 
the long-term average of the in situ ALT measurements at this node and estimated the expected seasonal deformation using Equation (3) below. We then assumed that this represented a known deformation and used this location as the reference point to calibrate the subsidence for the entire domain.

Accurate InSAR measurements require high coherence. Coherence is the correlation of radar phase between the two SAR images and varies between zero and one, with one indicating a perfect match and zero a perfect mismatch. Coherence loss results from temporal changes in surface scattering characteristics, changes in viewing geometry, and noise in the SAR data. Temporal coherence loss increases with the time span between the two SAR scenes, although coherence typically persists for individual seasons and even for several years in tundra regions for C-band and L-band SAR data $[19,32,33]$. We found generally good coherence in the interferograms with values greater than 0.5 , which is consistent with our assumption that spurious effects such as radio frequency interference (RFI) and ionospheric Faraday rotation do not hinder the estimation of seasonal subsidence. Although other authors have reported RFI in InSAR data near Barrow [34], we found no evidence of RFI in the raw or processed InSAR data used in this study, and thus have made no attempt to correct for RFI.

We solved for 2006-2010 average seasonal subsidence for each pixel of the 20 interferograms using least squares regression. The subsidence per pixel measured by the $i$ th interferogram, $D_{i}$, constructed from SAR scenes acquired at times $t_{1, i}$ and $t_{2, i}$, can be represented as:

$$
D_{i}=R\left(t_{2, i}-t_{1, i}\right)+E\left(\sqrt{A_{2, i}}-\sqrt{A_{1, i}}\right)
$$

where $R$ is the subsidence rate, $E$ is the amplitude of seasonal subsidence, and $A_{1, \mathrm{i}}$ and $A_{2, \mathrm{i}}$ are the normalized, accumulated degree days of thawing (ADDT) at times $t_{1, \mathrm{i}}$ and $t_{2, \mathrm{i}}$ [21]. The first term on the right is the overall ground subsidence trend due to the melting of excess ground ice near the permafrost table, while the second is the average seasonal subsidence due to freezing and thawing of the active layer. We calculated $A_{1, \mathrm{i}}$ and $A_{2, \mathrm{i}}$ from air temperature records from National Oceanic and Atmospheric Administration (NOAA) Barrow Observatory (http://www.esrl.noaa.gov/gmd/obop/brw/) and normalized them such that the maximum value is one at the end of the thaw season. We estimated $R$ and $E$ for each pixel from the set of 20 interferograms by finding the least-squares solution to a linear system of equations [21]:

$$
\left[\begin{array}{c}
D_{1} \\
\vdots \\
D_{N}
\end{array}\right]=\left[\begin{array}{cc}
t_{2,1}-t_{1,1} & \sqrt{A_{2,1}}-\sqrt{A_{1,1}} \\
\vdots & \vdots \\
t_{2, N}-t_{2, N} & \sqrt{A_{2, N}}-\sqrt{A_{1, N}}
\end{array}\right]\left[\begin{array}{l}
R \\
E
\end{array}\right]
$$

where $N$ is the number of interferograms. The resulting estimate of $E$ represents the average seasonal subsidence from 2006 to 2010.

The uncertainty in $E$ for each pixel is the standard deviation of the residuals after removing the curve fit resulting from our least squares optimization [21]. The time period covered by the PALSAR data was too short to estimate statistically significant values of $R$, so the complete ReSALT product at Barrow consists of $E$, ALT, and associated uncertainties [35]. In this manuscript, ReSALT refers to the ALT portion of the product unless otherwise noted.

We estimated ALT for each pixel from $E$ assuming a vertical distribution of water in the soil column: 


$$
E=\frac{\rho_{w}-\rho_{i}}{\rho_{i}} \int_{0}^{A L T} P S d z
$$

where $P$ is soil porosity, $S$ is soil moisture fraction of saturation, $\rho_{w}$ is the density of water, and $\rho_{i}$ is the density of ice [21]. To model $P$ as a function of depth we assumed a surface organic layer with organic content decreasing exponentially with depth to pure mineral soil, resulting in soil porosity starting at $90 \%$ near the ground surface and decreasing to $\sim 45 \%$ at depths near the permafrost table [21]. We assumed the active layer is fully saturated $(S=1)$, which is very typical of the tundra areas surrounding Barrow and along the Alaskan Arctic coast [36]. We then numerically solved for ALT using Equation (3). The dominant sources of uncertainty in ReSALT are the uncertainties in $E$ followed by uncertainties in $S$ [21].

\subsection{ALT Comparison}

Our accuracy goal for ReSALT is to match observed ALT within observational uncertainty. Unless otherwise noted, we refer to all probe and GPR ALT measurements as "observed". To assess accuracy, we first calculated the residuals between ReSALT and observed ALT:

$$
r_{n}=\operatorname{ReALT}_{n}-A L T_{o, n}
$$

where $r_{n}$ is the residual and $A L T_{o, n}$ is the observed ALT for the $n$th pixel. The average $r_{n}$ for all pixels is the bias between the ReSALT and observed ALT. We chose the $\chi^{2}$ statistic to compare ReSALT and observed ALT because it accounts for observational uncertainty:

$$
\chi_{n}^{2}=\left(\frac{r_{n}}{\varepsilon_{o, n}}\right)^{2}
$$

where $\varepsilon_{o, n}$ is the uncertainty in $A L T_{o, n}$ for the $n$th pixel. The overall $\chi^{2}$ is

$$
\mathrm{x}^{2}=\frac{1}{N} \sum_{1}^{N} \mathrm{x}_{n}^{2}
$$

where $N$ is the total number of pixels with observed ALT. We calculated the residuals, biases, and $\chi^{2}$ for all observed ALT and for each site individually (See Table 2).

To simplify our evaluation of ReSALT accuracy, we grouped the $\chi^{2}$ values into three categories: an ideal match, a good match, and no match, illustrated schematically in Figure 2. An ideal match occurs when $\chi^{2}<1$, indicating that the ReSALT and observed ALT agree within uncertainty. Physically, this means the ReSALT and observed ALT are statistically identical, the ideal objective for comparing remotely-sensed and ground-based measurements. A good match occurs when $A L T_{o, n}$ falls within the ReSALT uncertainty, but ReSALT does not fall within the observed ALT uncertainty. This occurred frequently since the uncertainty in ReSALT is roughly double the uncertainty in $A L T_{o, n}$. No match occurs when only the uncertainty bars overlap or do not overlap at all. Variation within these categories has little physical meaning: a $\chi^{2}$ of 0.5 is not "better" than 0.9 , since both are statistically identical. This simple classification system allowed us to quickly identify where ReSALT and observed ALT agreed and where they did not. 


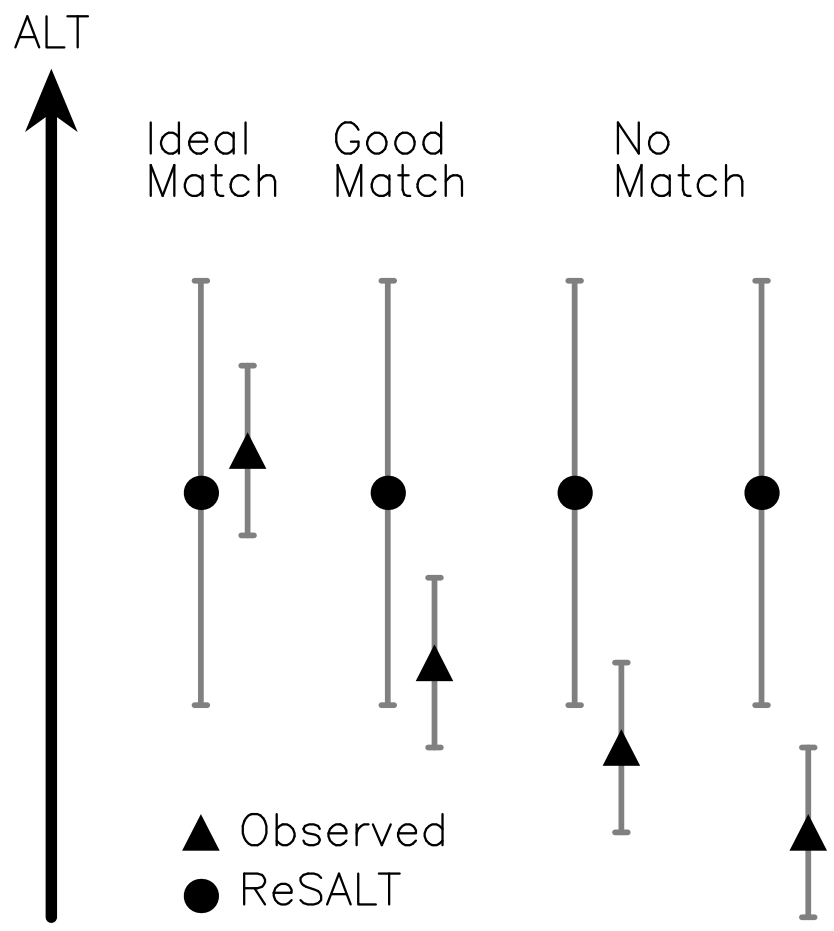

Figure 2. A schematic diagram showing the three classes of $\chi^{2}$ used to evaluate ReSALT. An ideal match occurs when ReSALT and observed active layer thickness (ALT) fall into each other's uncertainty bars. A good match occurs when the observed ALT falls within the ReSALT uncertainty, but ReSALT does not fall within the observed ALT uncertainty. No match occurs when only the uncertainty bars overlap or do not overlap at all.

Table 2. Summary of Ground Penetrating Radar (GPR) results.

\begin{tabular}{cccccccc}
\hline Site & $\begin{array}{c}\text { Velocity } \\
(\mathbf{m} / \mathbf{n s})\end{array}$ & $\begin{array}{c}\text { Velocity } \\
\text { Uncertainty }(\mathbf{m} / \mathbf{n s})\end{array}$ & $\begin{array}{c}\text { VWC } \\
(-)\end{array}$ & $\begin{array}{c}\text { VWC } \\
\text { Uncertainty }(-)\end{array}$ & $\begin{array}{c}\text { Average } \\
\text { ALT }(\mathbf{c m})\end{array}$ & $\begin{array}{c}\text { RMSE } \\
(\mathbf{c m})\end{array}$ & $\begin{array}{c}\text { ALT Uncertainty } \\
(\mathbf{c m})\end{array}$ \\
\hline Big Spot & 0.036 & 0.005 & 0.75 & 0.10 & $37 \pm 8$ & 5 & 6.83 \\
Big Spot peat & 0.036 & 0.004 & 0.96 & 0.12 & & & \\
Big Spot upland & 0.044 & 0.012 & 0.60 & 0.16 & & & \\
CALM & 0.042 & 0.009 & 0.62 & 0.12 & $40 \pm 8$ & 7 & 8.40 \\
CALM peat & 0.035 & 0.009 & 0.97 & 0.24 & & & \\
CALM upland & 0.047 & 0.014 & 0.56 & 0.16 & & & \\
Central Plain & 0.041 & 0.007 & 0.64 & 0.10 & $35 \pm 6$ & 6 & 7.59 \\
Nunavak River & 0.038 & 0.010 & 0.70 & 0.18 & $32 \pm 6$ & 6 & 7.59 \\
\hline
\end{tabular}

\section{Results}

\subsection{ReSALT}

The seasonal subsidence and associated ALT show broad spatial variability across the domain, with slightly higher values in many of the DTLBs and lower values in some river drainage basins (Figure 3). The average seasonal subsidence over the $200 \mathrm{~km}^{2}$ covered by ReSALT is $1.8 \pm 0.6 \mathrm{~cm}$ and the area average ALT is $28.4 \pm 11.8 \mathrm{~cm}$. The average ALT uncertainty was $16.1 \pm 5.5 \mathrm{~cm}$, resulting in an average relative uncertainty between $40 \%$ and $50 \%$. Many of the DTLBs show higher ALT than the 
surrounding tundra. Open water does not produce a coherent InSAR signal, so lakes with open water are left transparent. Pixels with a coherent signal can sometimes encroach into the lake itself because of the InSAR phase filtering, the area averaging we used to reduce uncertainty and because water along the shoreline often has enough vegetation to produce detectable backscatter.
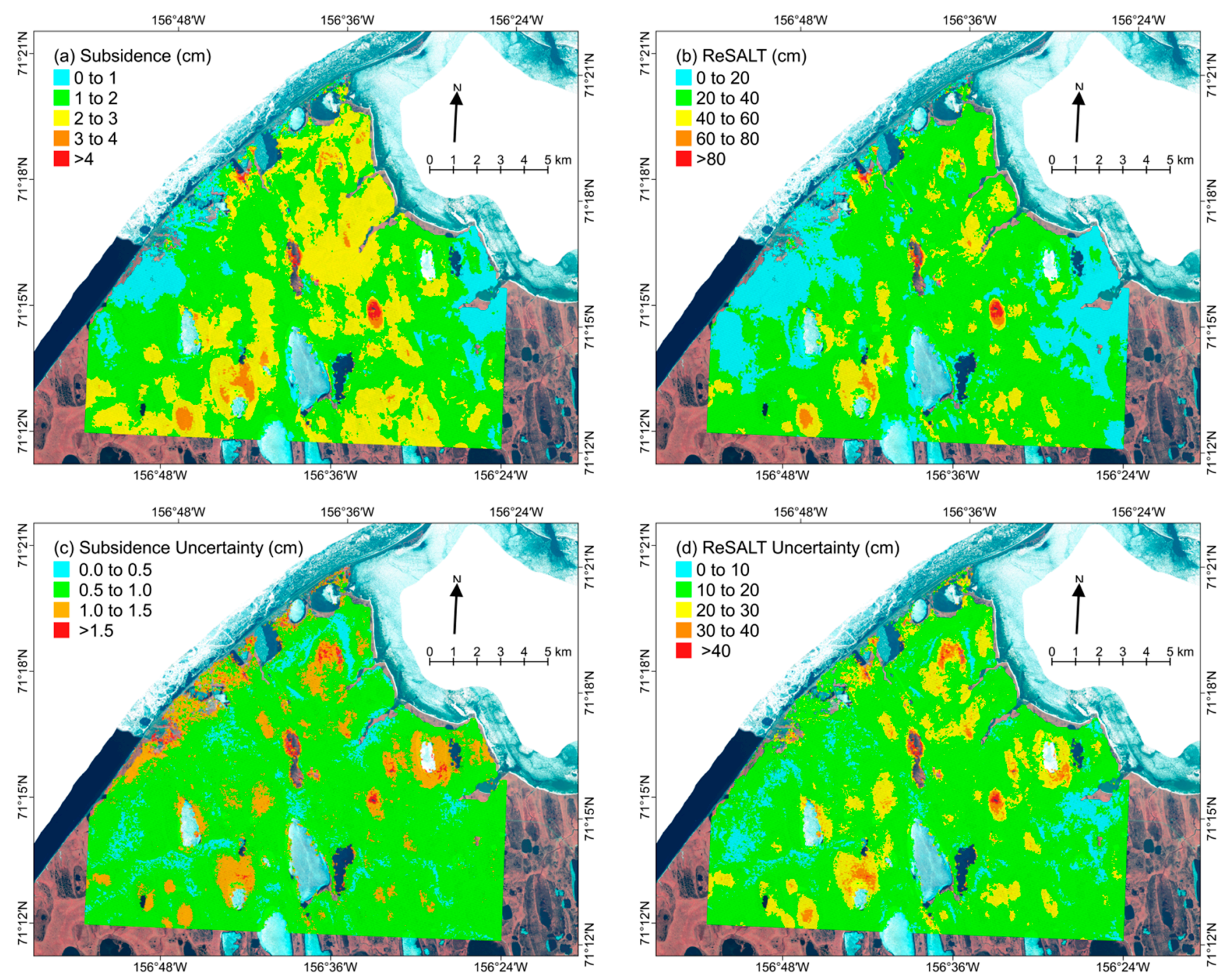

Figure 3. The 2006-2010 average seasonal subsidence from Interferometric Synthetic Aperture Radar (InSAR) (a); ReSALT (b) and associated uncertainties (c,d). Locations with no coherent signal are left transparent.

The lower limit on seasonal subsidence detectable using our current InSAR technique varies between 0.5 and $1.0 \mathrm{~cm}$. Around the Nunavak and Mayoeak rivers on the east and west edges of the domain, the seasonal subsidence and uncertainty are similar in magnitude, indicating the signal to noise ratio is near one and the subsidence is difficult to separate from the background noise in the InSAR data. The signal to noise ratio is greater than one in only $\sim 12 \%$ of the domain.

\subsection{GPR Results}

GPR accurately detected the spatial variation of ALT across the ice wedge and polygon landscape ubiquitous around Barrow with a deeper active layer over ice wedges, as demonstrated at 10 and $23 \mathrm{~m}$ 
along a calibration transect (Figure 4). For this probing survey, one of several at the Central Plain site, we evenly spaced individual traces at $50 \mathrm{~cm}$. We applied the $\chi^{2}$ test and $72 \%$ of the GPR traces were either an ideal or good match with the probe data. The $3.0 \mathrm{~cm}$ GPR uncertainty shown here represents wave velocity uncertainty for this one probing survey. The difference between the means of the GPR and probe data was not statistically significant based on a student t-test at a $95 \%$ confidence, therefore confirming validity of our approach. We performed a total of 16 probing surveys, an average of four surveys per site, with similar results.

(a) Radargram at Central Plain
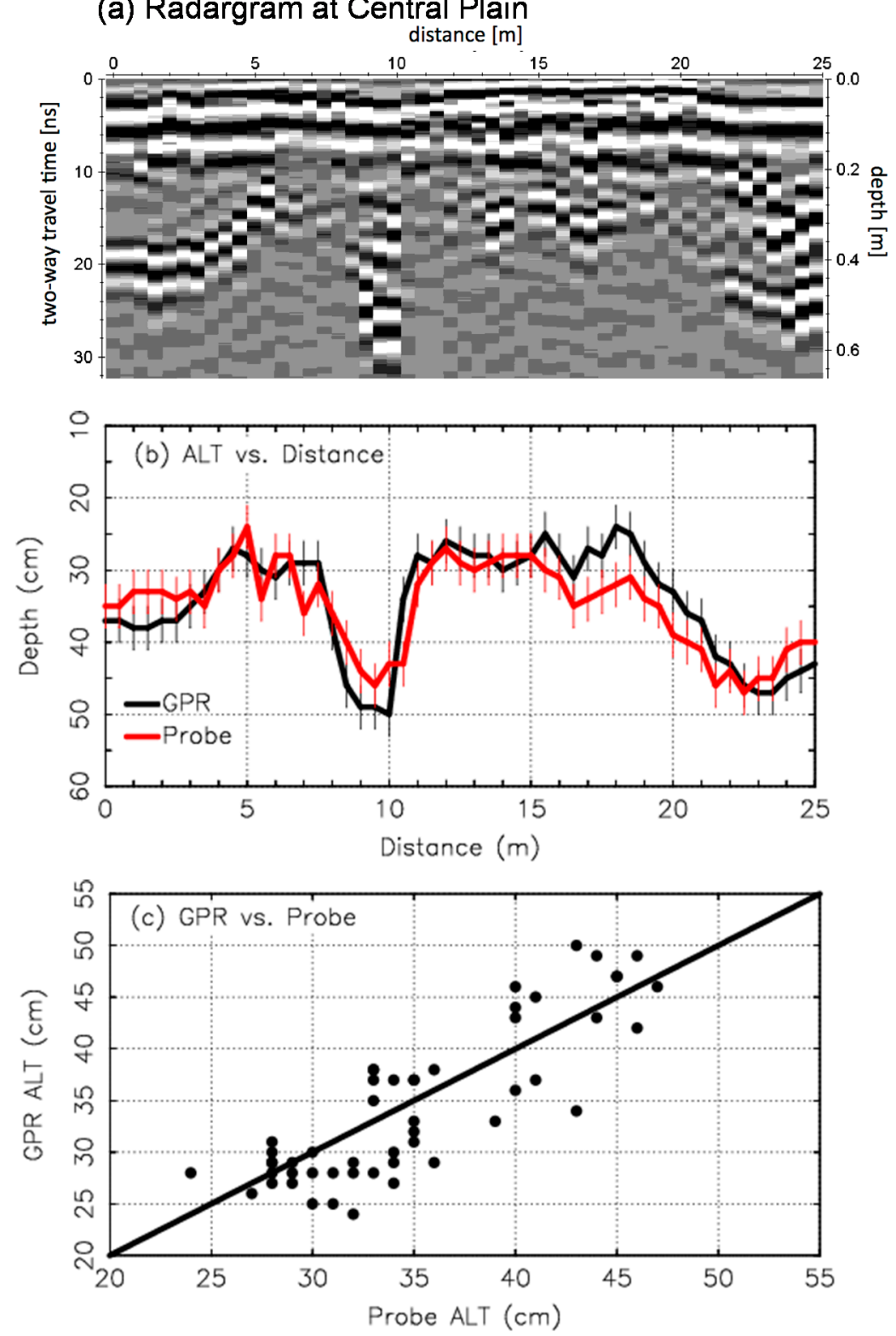

Figure 4. Radargram (a); GPR and probe ALT as a function of distance (b) and a scatterplot of GPR vs. probe ALT (c) for a survey at the Central Plain site. The active layer deepened when the track crossed over ice wedges at 10 and $23 \mathrm{~m}$.

Table 2 summarizes the GPR measurements for all four validation sites. The primary source of uncertainty in measured ALT was variation in wave velocity due to local variability in soil water content in the active layer. Missing GPS data prevented us from calibrating the GPR data using all 
probe points at Nunavak River, resulting in a high uncertainty and a probable bias towards wetter conditions. At Big Spot and CALM we were able to collect calibration probes in the residual ponds (peat), and the raised, undisturbed tundra outside of the DTLBs (upland), resulting in estimates of velocity, VWC and ALT uncertainty for different types of terrain within the two sites. However, we did not attempt to differentiate between the various land forms, so we show only the overall average ALT and uncertainties for the entire site and the corresponding overall uncertainties for each site used in our ReSALT evaluation.

\subsection{ReSALT Validation}

ReSALT matches observed ALT at Central Plain and CALM well, but greater than observed at Big Spot and less than observed at Nunavak River (Table 3). We show the GPR and probe data for the CALM sites separately because they were collected by different means, but both datasets compare similarly with ReSALT. Based on the $\chi^{2}$ values, ReSALT shows an ideal match at Central Plain and a good match at CALM, but no match at Big Spot and Nunavak River. We compared 1373 ReSALT pixels to observed ALT and 74\% show either an ideal or good match with observed ALT values. At the Big Spot and CALM sites, $77 \%$ to $86 \%$ of the pixels showed either an ideal or good match with observed values, yet the overall $\chi^{2}$ values are greater than one. Big Spot and Nunavak River have similar $\chi^{2}$ values, yet Big Spot has only $21 \%$ no matches compared to $97 \%$ at Nunavak River. To explain these results, we compared ReSALT with the observed ALT at each site in detail.

Table 3. Comparisons between ReSALT and GPR ALT at the four validation sites.

\begin{tabular}{|c|c|c|c|c|c|c|}
\hline Statistic & All & Big Spot & CALM GPR & CALM Probe & Central Plain & Nunavak River \\
\hline ReSALT ALT $(\mathrm{cm})$ & $36 \pm 19$ & $48 \pm 23$ & $33 \pm 10$ & $37 \pm 8$ & $39 \pm 2$ & $4 \pm 2$ \\
\hline Observed ALT $(\mathrm{cm})^{1}$ & $38 \pm 8$ & $37 \pm 8$ & $40 \pm 8$ & $36 \pm 8$ & $35 \pm 6$ & $32 \pm 6$ \\
\hline Bias $(\mathrm{cm})$ & -1.7 & 10.3 & -6.5 & 0.8 & 4.0 & -28.5 \\
\hline Number Grid Cells & 1373 & 441 & 637 & 115 & 81 & 99 \\
\hline$\chi^{2}(-)$ & 6.2 & 11.5 & 1.9 & 2.5 & 0.9 & 14.7 \\
\hline Ideal Match (\%) & 45 & 32 & 56 & 62 & 65 & 0 \\
\hline Good Match (\%) & 29 & 47 & 21 & 26 & 35 & 3 \\
\hline No Match $(\%)$ & 26 & 21 & 23 & 12 & 0 & 97 \\
\hline
\end{tabular}

${ }^{1}$ Observed refers to either GPR or probed ALT.

ReSALT at Central Plain showed either an ideal or good match with observed ALT (Figure 5). Gangodagamage et al. [13] and ReSALT showed similar ALT of 30-40 cm for an area east of Central Plain (Figure 5a). The matrix of high-center polygons at Central Plain was representative of all undisturbed tundra outside of DTLBs that we encountered at all validation sites. These conditions are very close to the idealized conditions represented in the ReSALT retrieval algorithm, resulting in an ideal overall match with the observed ALT. 

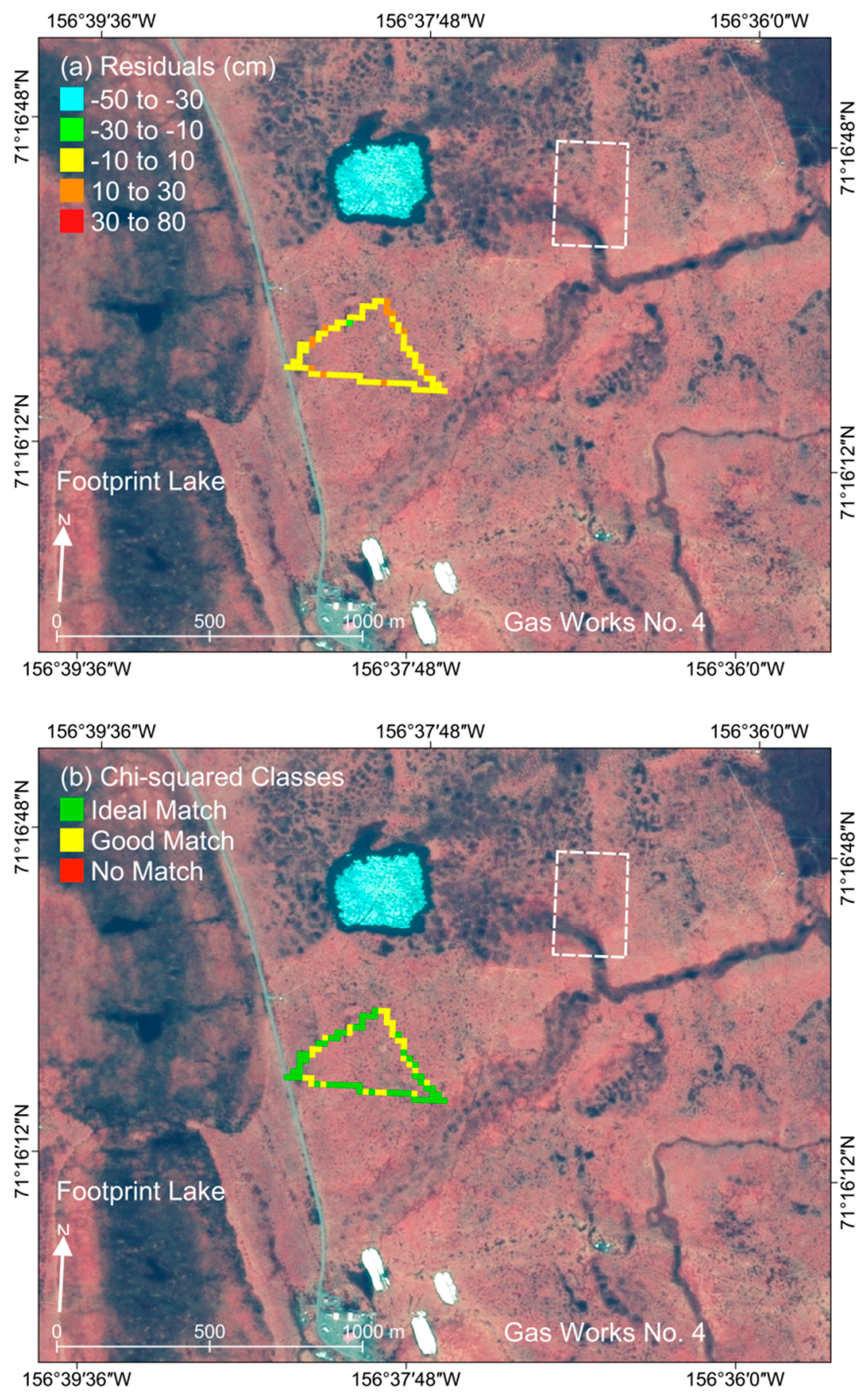

Figure 5. Residuals (a) and $\chi^{2}$ classes (b) between the GPR ALT and ReSALT at the Central Plain Site. The Central Plain site consisted of high-center polygons typical of undisturbed tundra around Barrow and well represented in the idealized ReSALT retrieval algorithm; The white square in (a) indicates where Gangodagamage et al. [13] estimated ALT using LiDAR.

ReSALT showed ideal or good matches with the GPR ALT in the three of the four DTLBs surveyed at Big Spot, but greatly overestimated ALT in Big Spot, explaining the overall positive bias and large $\chi^{2}$ (Figure 6). Big Spot had a large amount of standing water, but the SAR waves reflected off the vertical grass blades to produce a detectable, coherent signal. The spatial anomaly in Big Spot was directly over the residual pond in the center of the DTLB, hinting that the ReSALT retrieval 
algorithm may be detecting seasonal variations in water level in addition to seasonal subsidence in the active layer. However, DTLBs 2 and 3 directly east and west of Big Spot also had standing water with no obvious biases in ReSALT.
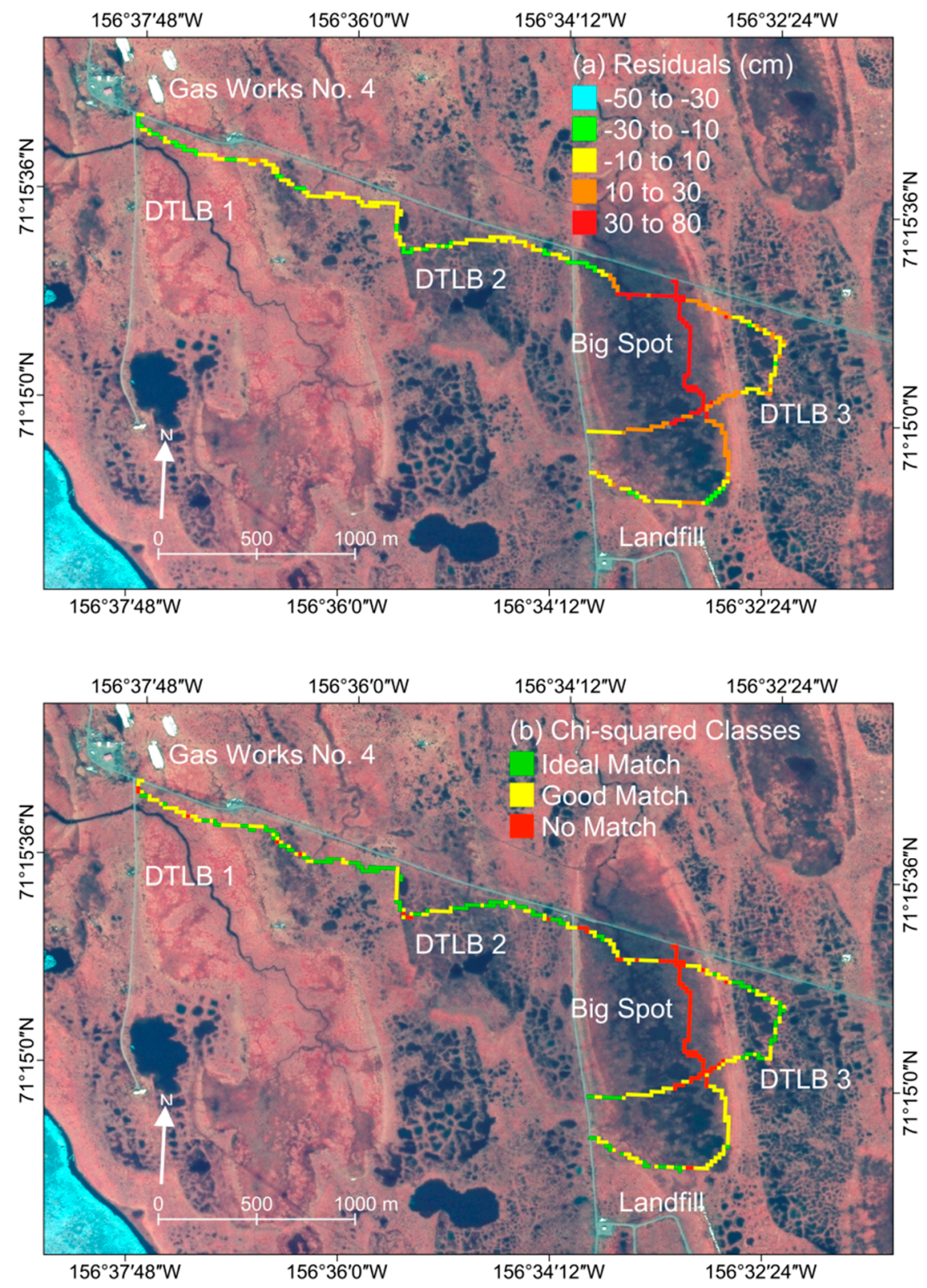

Figure 6. Residuals (a) and $\chi^{2}$ classes (b) between the GPR ALT and ReSALT at Big Spot. The Big Spot site consisted of a series of drained thermokarst lake basins (DTLB) with Big Spot drained thermokarst lake basin (DTLB) itself showing the largest ReSALT values in the entire domain.

At the CALM site, ReSALT showed an ideal or good match with observed ALT from GPR and probing in some locations, but not others, depending on local hydrologic and geomorphic factors (Figure 7). The CALM site consisted of a narrow strip of undisturbed tundra running north and south with DTLB 4 to the east and the CALM DTLB to the west. The 1-km grid of the U1 CALM site appears on the eastern edge of the site and extends into both DTLBs. The Central Marsh River drained the southernmost portion of the CALM DTLB, resulting in non-saturated soils that violated our 
assumption of fully saturated soils and resulted in an underestimate of observed ALT. ReSALT showed an ideal or good match with observed ALT in the undisturbed tundra and much of the DTLB.
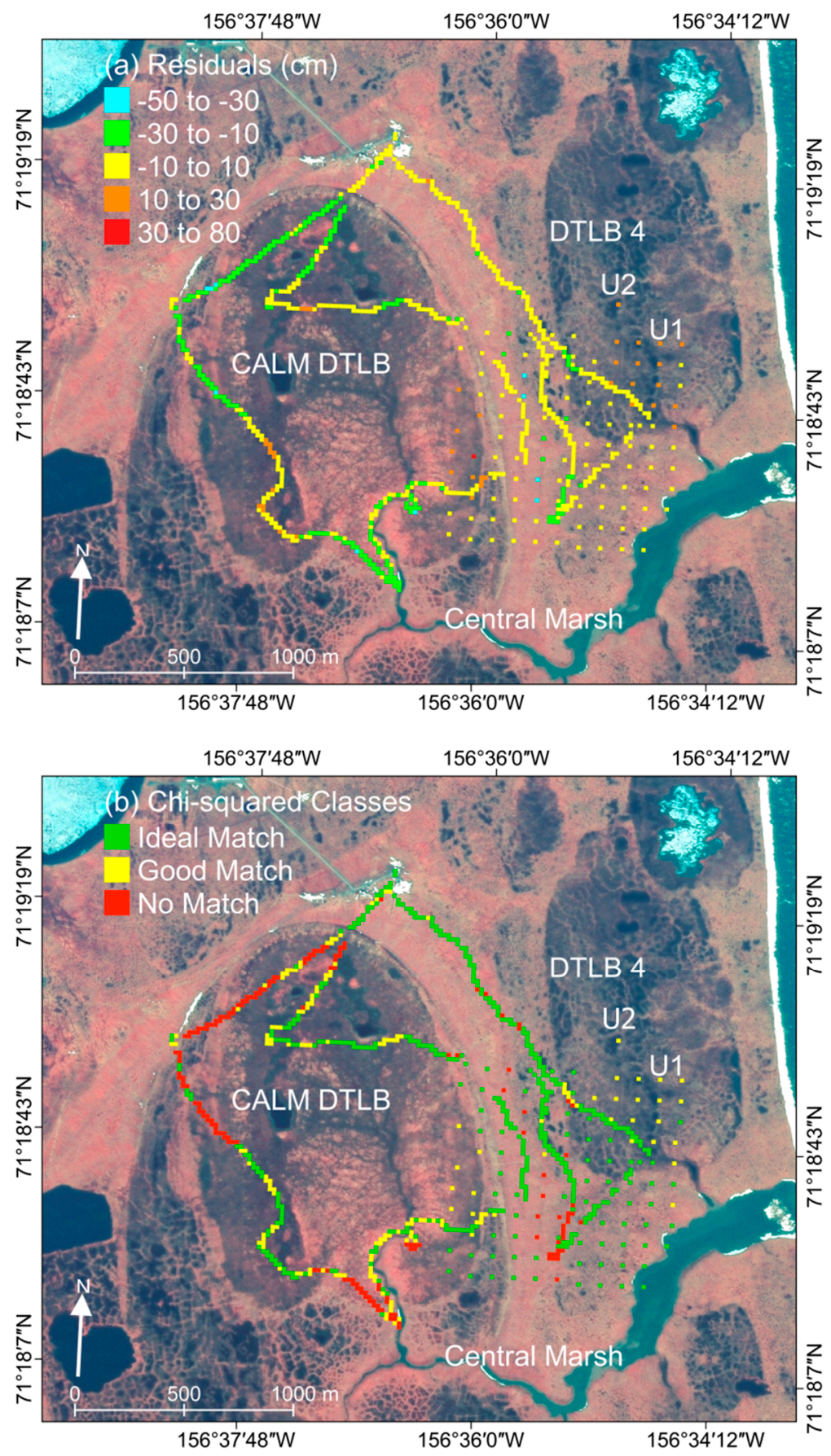

Figure 7. Residuals (a) and $\chi^{2}$ classes (b) between the observed ALT and ReSALT at the Circumpolar Active Layer Monitoring (CALM) Site. The site consists of two DTLBs separated by a narrow strip of undisturbed tundra and includes the U1 and U2 CALM sites. The GPR data appear as lines, the U1 CALM data appears as a 1-km grid in the southeast, and the U2 CALM data as a single pixel in DTLB 4.

ReSALT was less than observed ALT along the old shoreline of the CALM DTLB due to the presence of gravel. The old shoreline consisted of a two-meter bluff containing large amounts of 
gravel, which, in many places, made probing impossible. The ReSALT retrieval algorithm does not account for gravel reducing the soil porosity, resulting in an underestimate compared to the observed ALT. Gravel deposits resulted in no matches between ReSALT and observed ALT in the northwest section of the DTLB and in the center of the U1 grid.

The Big Spot and CALM DTLBs contained similar amounts of standing water (Figure 8). However, unlike the strong anomaly at the Big Spot DTLB, ReSALT showed either an ideal or good match with observed ALT across the entire residual pond in the CALM DTLB. We surveyed six DTLBs between the Big Spot and CALM sites and, except for Big Spot, all showed ideal or good matches with observed ALT.

\section{(a) Big Spot}

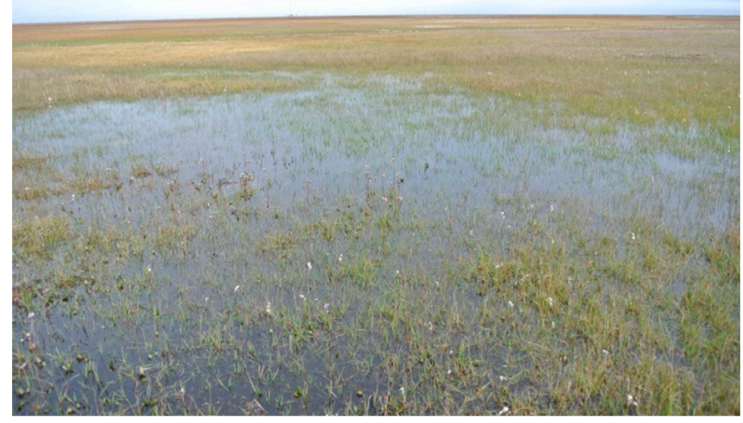

(b) CALM Lakebed

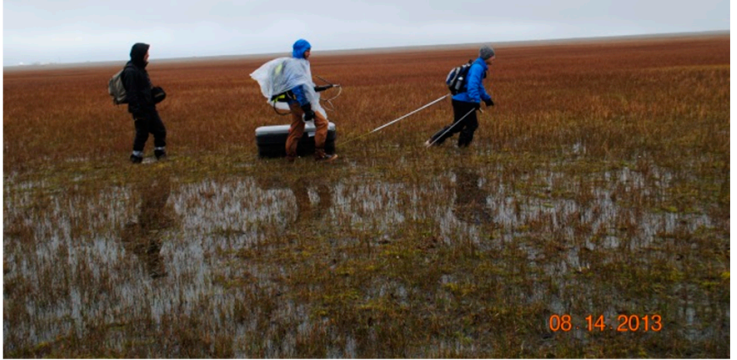

Figure 8. The Big Spot (a) and CALM (b) lake basins had similar amounts of standing water, but the ReSALT retrieval algorithm estimated much stronger seasonal subsidence at Big Spot DTLB; Photo credits: Andrew Parsekian (a) and Kevin Schaefer (b).

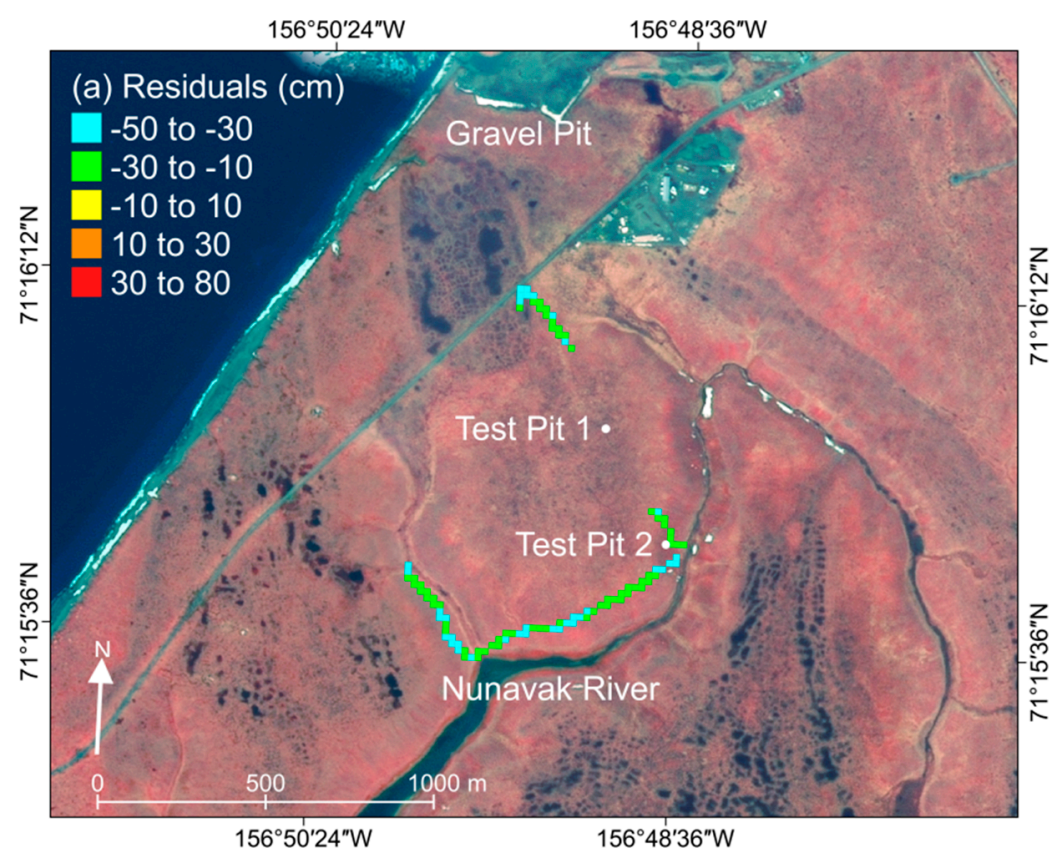

Figure 9. Cont. 


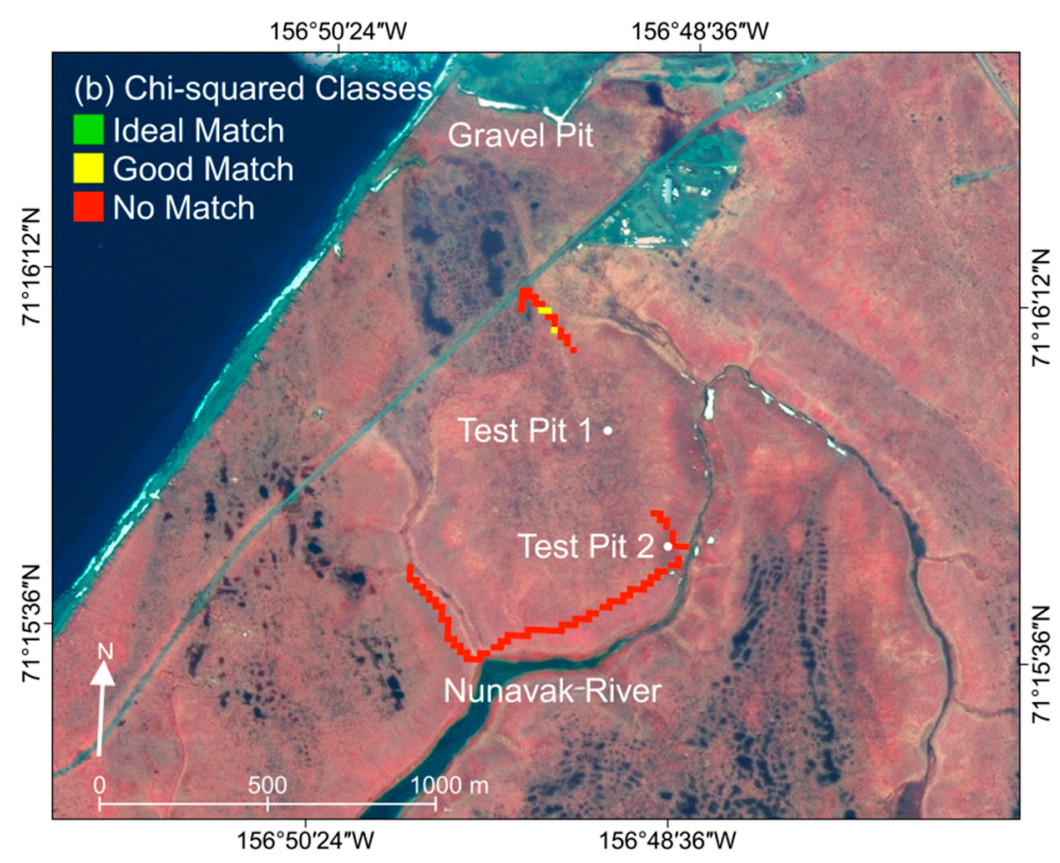

Figure 9. Residuals (a) and $\chi^{2}$ classes (b) between the GPR ALT and ReSALT at the Nunavak River Site. The site consists of well-drained soils in the upper Nunavak drainage basin.

ReSALT was much smaller than observed ALT at the Nunavak River site. The ReSALT retrieval algorithm measured very low seasonal subsidence near the $0.5 \mathrm{~cm}$ detection limit for the entire area around the Nunavak River, resulting in an area average ReSALT of only $4 \mathrm{~cm}$, compared to $32 \mathrm{~cm}$ measured by GPR. There are extensive gravel deposits around Barrow, especially near the coast, but we found no evidence of gravel along the GPR tracks that could explain the low seasonal subsidence. Test pit 1 showed drained, undersaturated soil while test pit 2 showed fully saturated soil, consistent with drainage towards to Nunavak River (Figure 9). The average VWC was $0.70 \pm 0.18$, indicating the soil water content was not significantly different than the other sites. However, due to a problem with our GPS unit, we lost much of the GPR data in the well-drained area at the center of the site, so this VWC value may be biased towards the saturated, wetter conditions near the Nunavak River.

\section{Discussion}

ReSALT matches observed ALT in undisturbed tundra and most DTLBs corresponding to $~ 76 \%$ of the domain, consistent with the assumption of fully saturated soils in the ALT retrieval algorithm. We obtained this by determining where at each site ReSALT did not match observations and applying those conditions to the entire domain. We estimate that ReSALT was less than observed ALT in 22\% of the domain where InSAR measured seasonal subsidence less than $1 \mathrm{~cm}$. The ReSALT retrieval algorithm underestimated the ALT in locations containing gravel which we estimate to be $\sim 1 \%$ of the domain based on the fraction of the GPR surveys where we encountered gravel. The ReSALT retrieval algorithm measured excessively large seasonal subsidence in some DTLBs representing $\sim 1 \%$ of the domain, resulting in large overestimates of ALT. The accuracy of ReSALT relative to observed ALT from GPR and probing depended on local hydrology and geomorphology. We examined in greater 
detail the areas where we do not see a good match between ReSALT and observed ALT, focusing on potential causes and testing possible corrections (Figure 10).

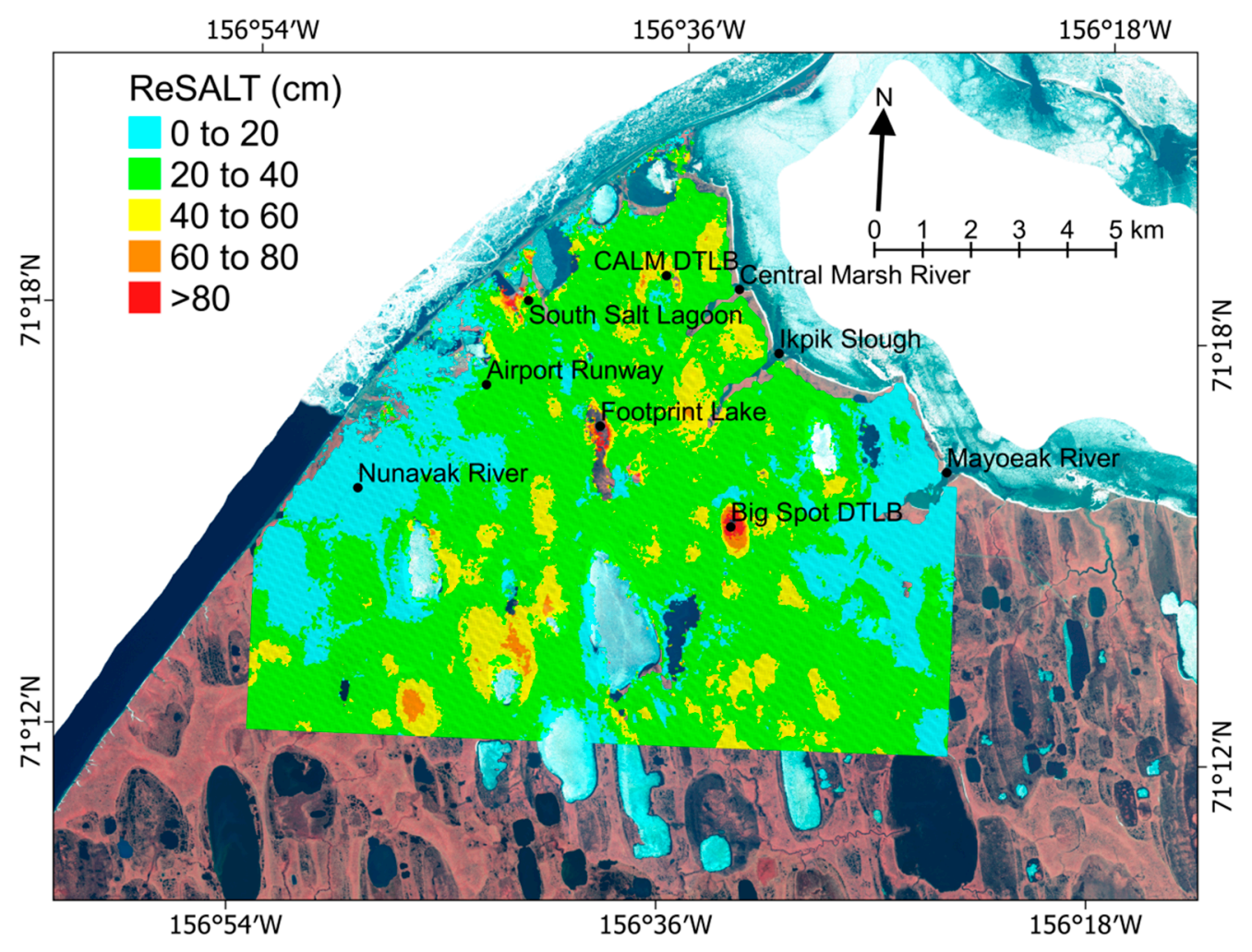

Figure 10. The ReSALT retrieval algorithm underestimated ALT around the Nunavak and Mayoeak Rivers due to a combination of unsaturated soils and InSAR data artifacts. The ReSALT retrieval algorithm underestimated ALT in areas with gravel deposits, such as the airport runway and the CALM DTLB. The ReSALT retrieval algorithm greatly overestimated ALT in Big Spot, Footprint Lake, and Big Spot DTLBs.

\subsection{Soil Water Content}

The ReSALT retrieval algorithm underestimates ALT in regions with seasonal subsidence of $1.0 \mathrm{~cm}$ or less due to under-saturated soils and potential artifacts in the InSAR data. The areas of low subsidence cover $\sim 22 \%$ of the domain and are concentrated in two river basins: Nunavak River in the west and the Mayoeak River in the east (Figure 10). This suggests that the cause of the low subsidence is related to well-drained, under-saturated soils near rivers. However, Ikpik Slough and Central Marsh River show no signs of low subsidence, indicating the pattern is not universal and suggesting potential InSAR artifacts may also contribute to the low subsidence.

To test the influence of soil moisture, we estimated the saturation fraction required at Nunavak River for ReSALT to match observed ALT. Below saturation, the soil water can expand into air spaces between soil grains as it freezes, reducing the frost heave. For low clay soils such as found around Barrow, at roughly $74 \%$ saturation the ice entirely expands into the soil air space and the frost heave is zero [37]. We scaled Equation (3) to account for this effect using a normalized curve fit of observed frost heave as a function of saturation [37]. We found that reducing $S$ in the ReSALT retrieval algorithm at Nunavak River to $\sim 77 \%$ would increase ReSALT to $32 \mathrm{~cm}$, matching the observed values. 
This is consistent with the observed VWC of 0.7 which corresponds to $S$ of $\sim 80 \%$ based on the ReSALT porosity model. However, we cannot determine the actual saturation fraction because the uncertainty in VWC at Nunavak River is so large. Also, the other sites have similar values of VWC and do not show low subsidence and corresponding small ReSALT values. Under-saturated soils can clearly contribute to the ReSALT bias at Nunavak River, but cannot fully explain it.

These results indicate that spatially explicit knowledge of soil moisture could improve the ReSALT retrieval algorithm. Integrating a three dimensional soil water transport model or remotely sensed water content into the retrieval algorithm can provide the required spatial distribution of water content to improve ReSALT for well-drained soils. Further analysis is necessary to determine if the model can be relatively simple, such as one based on relative topography and slope, or may have to be a fully resolved ground water flow model at high resolution. On the other hand, remotely sensed soil water content from Soil Moisture and Ocean Salinity (SMOS) or the Soil Moisture Active Passive (SMAP) satellites could be directly used in the ReSALT retrieval algorithm, bypassing the need for a model.

\subsection{InSAR Data Artifacts}

Because InSAR measurements are affected by atmospheric noise, we tested whether the low seasonal subsidence anomalies could have been caused by a few interferograms affected by anomalously large amounts of atmospheric noise. The area of low subsidence extended far beyond the Nunavak River drainage, indicating the possibility of InSAR artifacts. For example, the area between the Nunavak River and Emaiksoun Lake consisted of low-center polygons with extensive standing water where we would normally expect the assumption of saturated soils in the ReSALT retrieval algorithm to be valid. To test if the anomaly could have been caused by an atmospheric noise artifact, we examined the effect of reprocessing ReSALT excluding all interferograms that used a scene which produced the strongest signal in the Nunavak River area. Removing this "outlier" SAR scene clearly shrunk the low subsidence spatial anomaly around the Nunavak River and increased ReSALT to $\sim 15 \mathrm{~cm}$, which is still half of what we observed. However, the region of low subsidence around the Nunavak River was a persistent signal in all interferograms, indicating the low subsidence in this area is probably real. For the final ReSALT product we did not remove the "outlier" SAR scene because doing so would approximately double the uncertainty everywhere and could have introduced unacceptable selection bias into the results.

Based on these tests and the results varying saturation fraction, we conclude that the $22 \%$ of the domain with low seasonal subsidence where the ReSALT retrieval algorithm underestimates ALT results from a combination of non-saturated soils and artifacts in the InSAR data. Correcting for well-drained soils requires detailed knowledge of the spatial distribution of soil moisture that is currently unavailable. Using better estimates of soil moisture combined with removal of outlier SAR scenes could increase ReSALT to the observed values of $32 \mathrm{~cm}$ for the Nunavak River site.

\subsection{Gravel Effects}

Areas containing a large amount of gravel result in an underestimate of ALT, as seen along the banks of the CALM DTLB (Figure 10). However, this effect was not seen in the other DTLBs we surveyed except the western edge of DTLB 4 and the southern edge of Big Spot. The CALM DTLB 
was the largest we surveyed, implying size might be a factor, but we could not form a general conclusion about the influence of gravel in DTLBs without surveying multiple DTLBs of varying size. Also, the ReSALT retrieval algorithm most likely underestimates the ALT along the coastline and around the vicinity of the town of Barrow, where gravel dominates the soil content. For example, the airport runway consists of a $3 \mathrm{~m}$ berm of crushed gravel with almost no seasonal subsidence, but almost certainly a deep active layer.

We explored a possible correction to the ReSALT retrieval algorithm by adjusting the assumed porosity profile to account for gravel in the active layer. Gravel takes up soil volume with porosity in fluvial deposits of $20 \%-40 \%$ [38-40], which is much less than the $45 \%$ we assume for mineral soil and $90 \%$ for the surface organic layer in our retrieval algorithm. Deeper deposits of gravel within the permafrost itself do not affect the ReSALT retrieval algorithm. In the CALM DTLB, rock size ranged from 2 to $4 \mathrm{~cm}$ in diameter, which indicates a porosity of $20 \%$ based on curve fits of observed porosity as a function of particle size [39]. This is $44 \%$ of the porosity we assumed for pure mineral soil, so to account for gravel we multiplied the vertical porosity profile in the ReSALT algorithm by 0.44 . The uncorrected ReSALT along the GPR track where we observed gravel varied between 20 and $30 \mathrm{~cm}$ while the GPR measured ALT between 40 and $50 \mathrm{~cm}$. Applying the gravel correction doubled ReSALT to between 40 and $50 \mathrm{~cm}$, resulting in ideal or good matches with the GPR data.

Applying this correction across the entire domain is more difficult because we lack detailed knowledge of gravel size and spatial distribution. We can apply this correction along the GPR track at the CALM site because we measured the gravel size and knew the location of the gravel deposits from our probing surveys. We did not encounter gravel everywhere in the CALM DTLB, only along the northern and western banks and the center of the U1 CALM grid (Figure 7). We encountered gravel in only $1 \%$ of our GPR surveys and did not encounter gravel in any of the other DTLBs we traversed except the western edge of DTLB 4 and the southern edge of Big Spot DTLB. Consequently, we cannot apply this correction across the domain or even within the CALM DTLB without more detailed knowledge of the spatial distribution of surface gravel. Such maps exist for the Barrow area, but integrating them into our retrieval algorithm is beyond the scope of this investigation and left for future work.

\subsection{Overestimation of ALT in DTLBS}

DTLBs showing ALT that is much higher than the surrounding tundra account for $1 \%$ of the domain and are highly suspect. There are three such features around Barrow: Big Spot DTLB, the "arch" of Footprint Lake, and the South Salt Lagoon east of Barrow (Figure 10). In addition, Liu et al. [41] observed another DTLB near Prudhoe Bay, Alaska called SAC basin that also showed anomalously large seasonal subsidence. All four of these anomalies occur in DTLBs, but we have not yet identified a common mechanism that can explain them. At SAC Basin, the spatial anomaly occurred in a slightly raised area of the DTLB away from the residual pond, indicating InSAR detected a seasonal variation in excess ground ice [32]. At Big Spot DTLB, the spatial anomaly occurs over standing water, hinting that the ReSALT retrieval algorithm may be detecting seasonal variations in water level. Footprint Lake showed strong seasonal subsidence, but low coherence due to melting ice wedges and eroding polygons indicative of massive thermokarst activity (Figure 5, adjacent to the Central Plain site). At Footprint Lake, subsidence due to thermokarst activity may be aliased onto the seasonal subsidence 
during the least squares optimization. The excess seasonal subsidence at South Salt Lagoon near Barrow could result from thermokarst activity, seasonal variability in water level, or both. The ReSALT retrieval algorithm is clearly detecting a signal in addition to the seasonal freezing and thawing of the active layer. However, isolating the root causes of the spatial anomalies in seasonal subsidence requires additional physical and hydrological observations.

\section{Conclusions}

The ReSALT retrieval algorithm accurately estimates the time-average ALT (2006-2010) within uncertainty of in situ observations in undisturbed tundra and DTLBs representing $\sim 76 \%$ of the area around Barrow over the period covered by the ALOS PALSAR data. The ReSALT resolution is $\sim 30 \mathrm{~m}$ and the average ALT around Barrow is $28.4 \pm 11.8 \mathrm{~cm}$. The uncertainty ranges between $40 \%$ and $60 \%$, although this approaches $100 \%$ in areas where the seasonal subsidence approaches the detection limit of $0.5 \mathrm{~cm}$. ReSALT shows strong spatial variability with deeper active layers in DTLBs compared to undisturbed tundra. The spatial resolution and coverage of ReSALT make it useful in any application requiring knowledge of the spatial distribution of ALT, from validation of models to evaluation of risks to human infrastructure. Our evaluation of the ReSALT product at Barrow indicates that InSAR is an effective way to remotely sense ALT at high spatial resolution over large areas.

Unsaturated soils and InSAR artifacts result in the ReSALT retrieval algorithm underestimating ALT by an average of $28 \mathrm{~cm}$ in $\sim 22 \%$ of the area around Barrow. The presence of gravel in the soil reduces soil porosity and results in an underestimate of ALT in $\sim 1 \%$ of the area around Barrow. The ReSALT retrieval algorithm also detects strong seasonal subsidence resulting in an overestimate of ALT in some DTLBs representing $\sim 1 \%$ of the area. Understanding the cause of these signals and improving the ReSALT retrieval algorithm will require integrating detailed in situ or remotely sensed measurements of actual soil moisture and spatially explicit maps of gravel size and distribution into the retrieval algorithm.

\section{Acknowledgments}

This study was in part supported by the U.S. National Aeronautics and Space Administration (NASA) grant NNX06AE65G as part of the North American Carbon Program. Support for Tingjun Zhang and for the field work support came from the U.S. National Science Foundation (NSF) grant ARC 0901962 to the University of Colorado at Boulder and ARC-1204013 to the Stanford University. Other support came from the U.S. National Oceanic and Atmospheric Administration (NOAA) grant NA07OAR4310115, NOAA grant NA09OAR4310063 to the University of Colorado at Boulder, and United States Geological Survey Cooperative Agreement Number G10AC00588 from the to the Alaska Climate Science Center. We thank Lee Slater (Rutgers University, Newark, NJ, USA) for lending the GPR antenna used in this investigation and Susan Maroney for help with the graphics.

\section{Author Contributions}

Kevin Schaefer wrote the paper, developed the comparison techniques between ReSALT and observed ALT, and made the gravel modifications to the ReSALT retrieval algorithm. Lin Liu, 
Albert Chen, and Howard A. Zebker did the primary InSAR data processing. Andrew Parsekian and Alessio Gusmeroli provided GPR expertise and equipment. All authors collected GPR data in the field.

\section{Conflicts of Interest}

The authors declare no conflict of interest.

\section{Appendix A}

Table A1. Interferograms used in this study and the individual PALSAR scenes used to construct them.

\begin{tabular}{ccccc}
\hline$\#$ & Scene 1 Date * & Scene 2 Date * & Scene 1 Granule & Scene 2 Granule \\
\hline $\mathbf{1}$ & 20060618 & 20060803 & ALPSRP021272170 & ALPSRP027982170 \\
$\mathbf{2}$ & 20060618 & 20080623 & ALPSRP021272170 & ALPSRP128632170 \\
$\mathbf{3}$ & 20060618 & 20090626 & ALPSRP021272170 & ALPSRP182312170 \\
$\mathbf{4}$ & 20060618 & 20090811 & ALPSRP021272170 & ALPSRP189022170 \\
$\mathbf{5}$ & 20060803 & 20090626 & ALPSRP027982170 & ALPSRP182312170 \\
$\mathbf{6}$ & 20070621 & 20070806 & ALPSRP074952170 & ALPSRP081662170 \\
$\mathbf{7}$ & 20070621 & 20080623 & ALPSRP074952170 & ALPSRP128632170 \\
$\mathbf{8}$ & 20070621 & 20090626 & ALPSRP074952170 & ALPSRP182312170 \\
$\mathbf{9}$ & 20070621 & 20090811 & ALPSRP074952170 & ALPSRP128632170 \\
$\mathbf{1 0}$ & 20070621 & 20100629 & ALPSRP074952170 & ALPSRP235992170 \\
$\mathbf{1 1}$ & 20070806 & 20080623 & ALPSRP081662170 & ALPSRP128632170 \\
$\mathbf{1 2}$ & 20070806 & 20090626 & ALPSRP081662170 & ALPSRP182312170 \\
$\mathbf{1 3}$ & 20070806 & 20090811 & ALPSRP081662170 & ALPSRP128632170 \\
$\mathbf{1 4}$ & 20070806 & 20100629 & ALPSRP081662170 & ALPSRP189022170 \\
$\mathbf{1 5}$ & 20070806 & 20100814 & ALPSRP081662170 & ALPSRP242702170 \\
$\mathbf{1 6}$ & 20080623 & 20090626 & ALPSRP128632170 & ALPSRP182312170 \\
$\mathbf{1 7}$ & 20080623 & 20090811 & ALPSRP128632170 & ALPSRP189022170 \\
$\mathbf{1 8}$ & 20090626 & 20090811 & ALPSRP182312170 & ALPSRP189022170 \\
$\mathbf{1 9}$ & 20090811 & 20100629 & ALPSRP189022170 & ALPSRP235992170 \\
$\mathbf{2 0}$ & 20100629 & 20100814 & ALPSRP235992170 & ALPSRP242702170 \\
\hline & & $*$ All dates are in YYYYMMDD format. &
\end{tabular}

\section{References}

1. Christiansen, H.H.; Etzelmüller, B.; Isaksen, K.; Juliussen, H.; Farbrot, H.; Humlum, O.; Johansson, M.; Ingeman-Nielsen, T.; Kristensen, L.; Hjort, J.; et al. The thermal state of permafrost in the nordic area during the international polar year 2007-2009. Perm. Periglac. Proc. 2010, 21, 156-181.

2. Romanovsky, V.E.; Drozdov, D.S.; Oberman, N.G.; Malkova G.V.; Kholodov A.L.; Marchenko, S.S.; Moskalenko, N.G.; Sergeev D.O.; Ukraintseva, N.G.; Abramov, A.A.; et al. Thermal state of permafrost in Russia. Perm. Periglac. Proc. 2010, 21, 136-155. 
3. Smith, S.L.; Romanovsky, V.E.; Lewkowicz, A.G.; Burn, C.R.; Allard, M.; Clow, G.D.; Yoshikawa, K.; Throop, J. Thermal state of permafrost in North America-A contribution to the international polar year. Perm. Periglac. Proc. 2010, 21, 117-135.

4. Osterkamp, T.E. Thermal state of permafrost in Alaska during the fourth quarter of the twentieth century (plenary paper). In Proceedings of the Ninth International Conference on Permafrost, Fairbanks, AK, USA, 29 June-3 July 2008, Vol. 2, pp. 1333-1338.

5. Romanovsky, V.E.; Smith, S.L.; Christiansen, H.H. Permafrost thermal state in the polar Northern Hemisphere during the international polar year 2007-2009: A synthesis. Perm. Periglac. Proc. 2010, 21, 106-116.

6. Van Everdinger, R. Multi-Language Glossary of Permafrost and Related Ground-Ice Terms (Revised 2005); National Snow and Ice Data Center/World Data Center for Glaciology: Boulder, CO, USA, 1998.

7. Shiklomanov, N.I.; Streletskiy, D.A.; Nelson, F.E.; Hollister, R.D.; Romanovsky, V.E.; Tweedie, C.E.; Bockheim, J.G.; Brown, J. Decadal variations of active-layer thickness in moisture-controlled landscapes, Barrow, Alaska. J. Geophys. Res. 2010, 115, G00I04.

8. Voigt, T.; Füssel, H.M.; Gärtner-Roer, I.; Huggel, C.; Marty, C.; Zemp, M. Impacts of Climate Change on Snow, Ice, and Permafrost in Europe: Observed Trends, Future Projections, and Socio-Economic Relevance; Technical Paper 2010/13; European Topic Centre on Air and Climate Change: Bilthoven, The Netherlands, 2010.

9. Romanovsky, V.E.; Smith, S.L.; Christiansen, H.H.; Shiklomanov, N.I.; Drozdov, D.S.; Oberman, N.G.; Kholodov, A.L.; Marchenko, S.S. Permafrost. Arctic Report Card 2011, 2011. Available online: http://www.arctic.noaa.gov/reportcard (accessed on 1 February 2014).

10. Burgess, M.M.; Smith, S.L.; Brown, J.; Romanovsky, V.; Hinkel, K. The Global Terrestrial Network for Permafrost (GTNet-P): Permafrost Monitoring Contributing to Global Climate Observations. Available online: http://ftp2.cits.rncan.gc.ca/pub/geott/ess_pubs/211/211621/ cr_2000_e14.pdf (accessed on 23 March 2015).

11. Brown, J.; Hinkel, K.M.; Nelson, F.E. The circumpolar active layer monitoring (CALM) program: Research designs and initial results. Polar Geog. 2000, 24, 165-258.

12. Streletskiy, D.A.; Shiklomanov, N.I.; Nelson, F.E.; Klene, A.E. 13 years of observations at Alaskan CALM sites: Long-term active layer and ground surface temperature trends. In Proceedings of the Ninth International Conference on Permafrost, Fairbanks, AK, USA, 29 June-3 July 2008, Vol. 2, pp. 1727-1732.

13. Gangodagamage, C.; Rowland, J.C.; Hubbard, S.S.; Brumby, S.P.; Liljedahl, A.K.; Wainwright, H.; Wilson, C.J.; Altmann, G.L.; Dafflon, B.; Peterson, J.; et al. Extrapolating active layer thickness measurements across Arctic polygonal terrain using LiDAR and NDVI data sets. Water Resour. Res. 2014, doi:10.1002/2013WR014283.

14. Nelson, F.E.; Shiklomanov, N.I.; Mueller, G.R.; Hinkel, K.M.; Walker, D.A.; Bockheim, J.G. Estimating active-layer thickness over a large region: Kuparuk River basin, Alaska, USA. Arct. Alp. Res. 1997, 29, 367-378. 
15. Pastick, N.J.; Jorgenson, M.T.; Wylie, B.K.; Minsley, B.J.; Ji, L.; Walvoord, M.A.; Smith, B.D.; Abraham, J.D.; Rose, J.R. Extending airborne electromagnetic surveys for regional active layer and permafrost mapping with remote sensing and ancillary data, Yukon Flats Ecoregion, Central Alaska. Perm. Periglac. Proc. 2013, 24, 184-199.

16. Wang, Z.; Li, S. Detection of winter frost heaving of the active layer of Arctic permafrost using SAR differential interferograms. In Proceedings of the IGARSS'99: Remote Sensing of the System Earth: A Challenge for the 21st Century, Hamburg, Germany, 28 June-2 July 1999; pp. 1946-1948.

17. Singhroy, V.; Couture, R.; Alasset, P.J.; Poncos, V. InSAR monitoring of landslides on permafrost terrain in Canada. In Proceedings of the IEEE 2007 International Geoscience and Remote Sensing Symposium, Barcelona, Spain, 23-28 July 2007; pp. 2451-2454.

18. Rykhus, R.P.; Lu, Z. InSAR detects possible thaw settlement in the Alaskan Arctic coastal plain. Can. J. Remote Sens. 2008, 34, 100-112.

19. Liu, L.; Zhang, T.; Wahr, J. InSAR measurements of surface deformation over permafrost on the North Slope of Alaska. J. Geophys. Res. 2010, 115, F03023.

20. Short, N.; Brisco, B.; Couture, N.; Pollard, W.; Murnaghna, K.; Budkewitsch, P. A comparison of TerraSAR-X, RADARSAT-2 and ALOS-PALSAR interferometry for monitoring permafrost environments, case study from Herschel Island, Canada. Remote Sens. Environ. 2011, 115, 3491-3506.

21. Liu, L.; Schaefer, K.; Zhang, T.; Wahr, J. Estimating 1992-2000 average active layer thickness on the Alaskan North Slope from remotely sensed surface subsidence. J. Geophys. Res. 2012, doi:10.1029/2011JF002041.

22. Hinkel, K.M.; Nelson, F.E. Spatial and temporal patterns of active layer thickness at Circumpolar Active Layer Monitoring (CALM) sites in northern Alaska, 1995-2000. J. Geophys. Res. 2003, doi:10.1029/2001JD000927.

23. Doolittle, J.A.; Hardisky, M.A.; Gross, M.F. A ground-penetrating radar study of active layer thickness in areas of moist sedge and wet sedge tundra, near Bethel, Alaska, USA. Arct. Alp. Res. 1990, 22, 175-182.

24. Schwamborn, G.D.; Wagner, D.; Hubberten, H.W. The use of GPR to detect active layers in young periglacial terrain of Livingston Island, Maritime Antarctica. Near Surf. Geophys. 2008, 6, 331-336.

25. Wollschlager, U.; Gerhards, H.; Yu, Q.; Roth, K. Multi-channel ground-penetrating radar to explore spatial variations in thaw depth and moisture content in the active layer of a permafrost site. Cryosphere 2010, 4, 269-283.

26. Hubbard S.S.; Gangodagamage, C.; Dafflon, B.; Wainwright, H.; Peterson, J.; Gusmeroli, A.; Ulrich, C.; Wu, Y.; Wilson, C.; Rowland, J.; et al. Quantifying and relating land-surface and subsurface variability in permafrost environments using LiDAR and surface geophysical datasets. Hydrogeo. J. 2012, doi:10.1007/s 10040-012-0939-y.

27. Gusmeroli, A.; Liu, L.; Schaefer, K.; Zhang, T.; Schafer, T.; Grosse, G. Active layer stratigraphy and organic layer thickness at a thermokarst site in Arctic Alaska identified using ground penetrating radar. Arct. Antarc. Alp. Res. 2015, in press. 
28. Engstrom, R., Hope, A.; Kwon, H.; Stow, D.; Zamolodchikov, D. Spatial distribution of near surface soil moisture and its relationship to microtopography in the Alaskan Arctic coastal plain. Nordic Hydrol. 2005, 36, 219-234.

29. Parsekian, A.D.; Slater, L.; Giménez, D. Application of ground-penetrating radar to measure near-saturation soil water content in peat soils. Water Resour. Res. 2012, 48, W02533.

30. Topp, G.C.; Davis, J.L.; Annan, A.P. Electromagnetic determination of soil-water content: Measurements in coaxial transmission lines. Water Resour. Res. 1980, 16, 574-582.

31. Lin, L.; Jafarov, E.E.; Schaefer, K.M.; Jones, B.M.; Zebker, H.A.; Williams, C.A.; Rogan, J.; Zhang, T. InSAR detects increase in surface subsidence caused by an Arctic tundra fire. Geophys. Res. Lett. 2014, doi:10.1002/2014GL060533.

32. Zebker, H.A.; Hensley, S.; Shanker, P.; Wortham, C. Geodetically accurate InSAR data processor. IEEE Trans. Geosci. Remote Sens. 2010, 48, 4309-4321.

33. Zebker, H.A.; Villasenor, J. Decorrelation in interferometric radar echoes. IEEE Trans. Geosci. Remote Sens. 1992, 30, 950-959.

34. Meyer, F.J.; Nicoll, J.B.; Doulgeris, A.P. Correction and characterization of radio frequency interference signatures in L-band synthetic aperture radar data. IEEE Trans. Geosci. Remote Sens. 2013, 51, 4961-4972.

35. Liu, L.; Schaefer, K.; Chen, A.; Gusmeroli, A.; Jafarov, E.; Panda, S.; Parsekian, A.; Schaefer, T.; Zebker, H.A.; Zhang, T. Pre-ABoVE: Remotely Sensed Active Layer Thickness (ReSALT) Barrow, Alaska, 2006-2011. Available online: http://dx.doi.org/10.3334/ORNLDAAC/1266 (accessed on 11 February 2015).

36. Zhang, T.; Osterkamp, T.E.; Stamnes, K. Effects of climate on the active layer and permafrost on the north slope of Alaska, USA. Perm. Periglac. Proc. 1997, 8, 45-67.

37. Dagesse, D.F. Freezing-induced bulk soil volume changes. Can. J. Soil Sci. 2010, 90, 389-401.

38. Carlin, P.A.; Reader, N.A. Structure, composition, and bulk properties of upland stream gravels. Earth Surf. Proc. Landforms 1982, 7, 349-365.

39. Frings, R.M.; Schüttrumpf, H.; Vollmer, S. Verification of porosity predictors for fluvial sand-gravel deposits. Water Resour. Res. 2011, 47, W07525.

40. Haynes, H.; Ockelford, A.M.; Vignaga, E.; Holmes, W.M. A new approach to define surface/sub-surface transition in gravel beds. Acta Geophys. 2012, 60, 1589-1606.

41. Liu, L.; Schaefer, K.; Gusmeroli, A.; Grosse, G.; Jones, B.M.; Zhang, T.; Parsekian, A.D.; Zebker, H.A. Seasonal thaw settlement at drained thermokarst lake basins, Arctic Alaska. Cryosphere 2014, doi:10.5194/tc-8-815-2014.

(C) 2015 by the authors; licensee MDPI, Basel, Switzerland. This article is an open access article distributed under the terms and conditions of the Creative Commons Attribution license (http://creativecommons.org/licenses/by/4.0/). 